\title{
A tributação progressiva dos rendimentos de capital
}

Progressive Taxation of Capital Income

La taxation progressive sur les revenus du capital

\section{Frederico Cantante}

\section{CpenEdition}

\section{Journals}

Edição electrónica

URL: http://journals.openedition.org/rccs/10239

DOI: $10.4000 /$ rccs. 10239

ISSN: 2182-7435

\section{Editora}

Centro de Estudos Sociais da Universidade de Coimbra

Edição impressa

Data de publição: 1 maio 2020

Paginação: 71-92

ISSN: 0254-1106

\section{Refêrencia eletrónica}

Frederico Cantante, "A tributação progressiva dos rendimentos de capital », Revista Crítica de Ciências Sociais [Online], 121 | 2020, posto online no dia 15 abril 2020, consultado o 17 abril 2020. URL : http:// journals.openedition.org/rccs/10239; DOI : https://doi.org/10.4000/rccs.10239 


\section{FREDERICO CANTANTE}

\section{A tributação progressiva dos rendimentos de capital}

Este artigo debruça-se sobre a tributação do rendimento das pessoas singulares em Portugal. Promover-se-á um olhar sobre a evolução do imposto sobre o rendimento (IRS) nas décadas anteriores à entrada em vigor do Código do IRS em 1989. Posteriormente, analisar-se-ão as continuidades dessa legislação face a um passado que se queria superar, em particular o cariz semi-dual do sistema de tributação dos rendimentos, que desafia os princípios da unicidade e progressividade fiscal inscritos na Constituição da República Portuguesa. Discutir-se-ão, por último, algumas soluções que poderiam introduzir maior justiça na tributação dos rendimentos de capital.

Palavras-chave: direito fiscal; impostos; Portugal; redistribuição do rendimento; tributação dos rendimentos.

\section{Introdução}

Portugal é um dos países do hemisfério norte que apresenta desigualdades mais elevadas na distribuição do rendimento. Esta realidade decorre principalmente dos hiatos gerados na distribuição primária do rendimento, seja no plano salarial, seja entre os fatores de produção. Os processos redistributivos têm, por definição, uma natureza corretiva e a sua tarefa é tanto mais exigente quanto mais elevadas são as desigualdades pré-redistributivas. ${ }^{1}$

A redistribuição do rendimento pelo Estado é feita por via de serviços públicos (no sentido em que estes significam um acréscimo de rendimento não monetário para as famílias), transferências sociais e impostos. Os impostos, no seu conjunto, têm um efeito redistributivo indireto porque permitem financiar quer os serviços públicos, quer as transferências sociais (em particular as de cariz não contributivo). Exercem também um papel

\footnotetext{
${ }^{1}$ Este artigo resultou de um trabalho de investigação levado a cabo no âmbito de uma tese de doutoramento financiada pela FCT (Bolsa de Doutoramento SFRH/BD/90934/2012), cuja versão sintetizada e revista foi publicada em livro (Cantante, 2019).
} 
redistributivo direto, principalmente ao nível da tributação do rendimento pessoal: o esforço fiscal é tanto maior quanto mais elevados são os rendimentos auferidos. Portugal é, aliás, um dos países em que o impacto dos impostos pessoais é mais elevado na diminuição da desigualdade.

A progressividade na tributação dos rendimentos pessoais convive com uma tendência internacional de sinal contrário, iniciada na década de 1980: a tributação proporcional dos rendimentos de capital. Este facto limita o alcance redistributivo dos sistemas fiscais e gera injustiças na tributação do rendimento.

Este artigo tem três objetivos fundamentais: promover um olhar sobre a evolução do sistema de tributação do rendimento em Portugal, desde meados do século XX até à atualidade, tendo como referência fontes legislativas e doutrinais; problematizar o seu cariz semi-dual; e propor coordenadas que permitam introduzir progressividade na tributação de certos rendimentos. Antes de desenvolver estas três linhas de análise, importa promover uma breve contextualização teórica da problemática em causa.

\section{Desigualdade económica e tributação}

A desigualdade na distribuição dos recursos económicos é um dos fenómenos mais marcantes dos nossos dias, não só pelos valores impressivos que assume em certas geografias, como pelos desafios políticos que coloca. A concentração do rendimento e da riqueza a nível global assume valores extremos quando comparada com as assimetrias no interior dos países. Milanović (2016) concluiu que 15,7\% do rendimento global está concentrado nos $1 \%$ do topo da população mundial (grupo que aufere um rendimento médio anual disponível de cerca de 71 mil dólares), valor que pode subir para os $28 \%$ se se tiver em linha de conta a subdeclaração de rendimentos nos inquéritos. Num estudo anterior, o mesmo autor (2011: 152) apurou que o rendimento dos $5 \%$ do topo da distribuição deste recurso era, em meados de 2000, 185 vezes superior ao dos 5\% mais pobres. Também no interior dos países a amplitude da desigualdade tem vindo a aumentar nas últimas décadas (Alvaredo et al., 2017; Atkinson, 2015; Piketty, 2013; OECD, 2008). Veja-se que, desde 1980, os $0,1 \%$ mais ricos "capturaram" uma parcela do crescimento económico equivalente à que foi acumulada pela metade mais pobre da população adulta mundial (Alvaredo et al., 2017: 40). Portugal é um dos países europeus em que a desigualdade económica é mais elevada. Os dados fiscais demonstram que, desde 1980, houve um aumento muito significativo da concentração do rendimento nos grupos do topo da distribuição deste recurso (Cantante et al., 2016; Alvaredo, 2010; Guilera, 2010). Tendência semelhante observa-se na distribuição dos ganhos salariais. 
Em 1985, os 1\% do topo auferiam 4,4\% do total dos ganhos salariais, 30 anos mais tarde, em 2015 , esse valor era já de $6,7 \%$, o que equivale a um aumento de cerca de 51\% (Cantante, 2019).

Um dos eixos explicativos que tem sido desenvolvido na interpretação do aumento da concentração da desigualdade nos grupos restritos do topo da distribuição no interior dos países prende-se com os efeitos da fiscalidade direta. $\mathrm{O}$ aumento da concentração do rendimento nos grupos mais favorecidos das populações de cada país ocorreu num contexto de diminuição da tributação dos rendimentos mais elevados. Esta correlação dever-se-á a duas razões. Em primeiro lugar, ao facto de a diminuição dos impostos nos grupos mais ricos permitir que estes criem um excedente de rendimento passível de ser reconvertido em rendimento futuro - o que tende a contribuir para a concentração deste recurso no topo. Em segundo lugar, porque a diminuição da taxa máxima aplicável aos ganhos salariais mais elevados assume-se como um estímulo à negociação de condições remuneratórias mais vantajosas por parte dos diretores e gestores de empresas e de outros grupos cuja capacidade negocial junto da entidade empregadora seja também elevada. O aumento do valor dessas taxas funcionaria, pelo contrário, como um desincentivo em relação à prossecução desse tipo de objetivos (Alvaredo et al., 2013, 2017; Piketty, 2013).

Tal como é referido por Brys et al. (2011), na primeira década do novo milénio, a taxa máxima aplicável aos rendimentos mais elevados foi reduzida em sete pontos percentuais ou mais em 12 países da OCDE. ${ }^{2}$ Essa é, aliás, uma tendência que se tem verificado ao longo das últimas décadas (OECD, 2014). A este respeito, Förster et al. (2014) recordam que, em meados da década de 1970, metade de um grupo de 16 países da OCDE (incluindo Portugal) aplicava aos rendimentos mais elevados taxas máximas que chegavam aos 70\% ou mais. Nos Estados Unidos (EUA), entre 1932 e 1980, a taxa média do imposto federal sobre os rendimentos mais elevados foi de $81 \%$, com um pico de cerca de $90 \%$ em meados da década de 1960 , e no Reino Unido esse valor variou entre $70 \%$ e $80 \%$ no período $1940-1980$ (Piketty, 2013: 818, 821).

Para além de uma redução das taxas marginais e máximas aplicáveis aos rendimentos mais elevados, um outro fenómeno tem caracterizado a evolução dos sistemas fiscais a nível global. A generalidade dos sistemas fiscais tem um conjunto variado de regimes que permitem que certos rendimentos, mesmo que enquadráveis nos patamares fiscais mais elevados,

${ }^{2}$ Bélgica, Dinamarca, Eslováquia, Eslovénia, França, Holanda, Hungria, Luxemburgo, México, Noruega, Polónia, República Checa. 
sejam tributados a taxas mais baixas. Vários estudos (Atkinson, 2015; OECD, 2014; Piketty, 2013; Landais et al., 2011) têm chamado a atenção para o facto de os sistemas fiscais assentarem em esquemas de tributação que opõem os rendimentos do trabalho e das pensões aos rendimentos de capital. Aqueles tendem a ser progressivos, no sentido em que as taxas aplicáveis elevam-se à medida que aumenta o seu montante, estes caracterizam-se pela sua proporcionalidade ou mesmo regressividade, já que são tributados a taxas proporcionais, tipicamente bastante inferiores às estatuídas para os rendimentos mais altos.

Ao longo do século xx e até hoje, os rendimentos do trabalho têm vindo a ganhar peso no rendimento total dos grupos mais abastados. De acordo com Alvaredo et al. (2013), se em 1980, nos EUA, 17\% dos 1\% com rendimentos de capital mais elevados posicionavam-se igualmente no grupo dos $1 \%$ de assalariados mais bem pagos, no ano 2000 esse valor aumentou para $27 \%$. E se, em 1980, 36\% dos trabalhadores que formavam os $1 \%$ do topo dos salários se incluíam no grupo dos $5 \%$ com rendimentos de capital mais elevados, 20 anos mais tarde, esse indicador aumentou para $50 \%$. No caso da Noruega, Aaberge et al. (2018) descobriram que entre os $1 \%$ do topo da distribuição dos salários, $91 \%$ posicionavam-se também na metade superior da distribuição dos rendimentos de capital e $36 \%$ entre o vintil superior. Essa associação é um pouco menos pronunciada quando se analisa a presença dos indivíduos com rendimentos de capital mais elevados na metade superior da distribuição dos rendimentos do trabalho, facto que decorre da existência de uma parte dos beneficiários de rendimentos de capital que são "capitalistas à moda antiga" (ibidem) terem poucos ou nenhuns rendimentos do trabalho.

O aumento acentuado dos rendimentos do trabalho no topo da distribuição deste recurso não significa que os rendimentos de capital tenham perdido a sua relevância no topo da distribuição dos recursos económicos. Mas essa predominância revela-se em grupos cada vez mais restritos da população: em França, mesmo depois da Primeira Guerra Mundial e no contexto do choque económico da crise de 1929, os rendimentos de capital eram a fonte económica principal do grupo dos $0,5 \%$ do topo. Nos dias de hoje, tal sucede apenas quando se analisa o grupo dos $0,1 \%$, de acordo com Piketty (2013).

\section{Os antecedentes do IRS}

$\mathrm{O}$ atual modelo de tributação dos rendimentos das pessoas singulares em Portugal tem a sua origem na reforma de 1988/1989, a qual marcou a adesão do país à "modernidade fiscal" (Faustino, 2014). Até aí a lei tributária 
caracterizava-se pela sua disfuncionalidade estrutural, ineficácia e injustiça. Produzida no final da década de 1950 e no início da seguinte, a lei fiscal em Portugal assentou até ao final da década de 1980 numa matriz essencialmente cedular.

A estrutura fiscal que se desenhou no período 1958-1963 compartimentou a tributação dos rendimentos em seis categorias: o imposto profissional, relativo ao trabalho dependente e ao trabalho independente dos profissionais liberais ou independentes; a contribuição industrial, vocacionada para a tributação do rendimento da atividade industrial e comercial; o imposto de capitais, relativo ao rendimento proveniente da aplicação de capitais; o imposto agrícola, relativo ao rendimento proveniente da atividade agrícola, silvícola e pecuária (este imposto praticamente não chegou a ser aplicado); a contribuição predial, aplicável ao rendimento da propriedade rústica e urbana; e o imposto de mais-valias. Ou seja, a tributação incidia sobre parcelas do rendimento pessoal ou empresarial, salários, dividendos, juros, mais-valias ou lucros. ${ }^{3}$

Esta lógica tributária cedular era secundada por "um imposto de sobreposição, o chamado imposto complementar, que tributava, de novo, com critérios de personalização, aquelas parcelas de rendimento", à exceção do imposto das mais-valias (Nabais, 2004: 456-457). Este imposto permitia - nomeadamente a sua secção A - unificar, personalizar parcialmente a tributação do rendimento das pessoas singulares, mas também aprofundar a progressividade fiscal. É neste sentido que se classifica a tributação do rendimento vigente na altura como sendo "dualista" (Nabais, 2004; Sanches, 1984): por um lado, existia um conjunto de impostos cedulares que incidiam exclusivamente sobre uma cédula ou parcela do rendimento; por outro, aplicava-se um imposto de sobreposição sobre estas cédulas que permitia tributar, de forma unificada e progressiva, a soma das parcelas do rendimento.

O imposto complementar já existia numa primeira formulação desde 1928, consistindo num "mero adicional" (Sanches, 1984: 192) em relação à contribuição predial rústica e urbana, à taxa complementar da contribuição industrial e ao imposto de capitais. A partir da década de 1960, o âmbito de aplicação deste imposto passou a incidir sobre a quase totalidade dos rendimentos, em particular nos rendimentos do trabalho (ibidem). O objetivo desta sobreposição fiscal era o de aproximar o esforço contributivo

\footnotetext{
3 Existiam também dois impostos destinados a taxar a transmissão do património: a Sisa, incidente sobre a transmissão onerosa de bens imóveis, e o imposto sobre as sucessões e doações, que incidia sobre a transmissão gratuita dos bens imóveis e móveis.
} 
dos indivíduos e famílias da sua real capacidade contributiva. Segundo Basto (2007: 22),

A ideia fora sempre a de fazer evoluir o sistema de tributação do rendimento no sentido do imposto único, fortalecendo o elemento personalizador do sistema, que era o imposto complementar, ao mesmo tempo que menos ênfase, e consequentemente menos receitas, ia sendo posto nas componentes reais ou seja nos impostos cedulares.

O imposto complementar começou por incidir sobretudo sobre os contribuintes mais favorecidos, mas foi progressivamente abarcando toda a população, à exceção dos mais pobres, devido ao facto de "os escalões do rendimento tributável e das deduções pessoais ficarem muito aquém dos ritmos da inflação" (Sanches, 1984: 188). Contudo, paradoxalmente, a democratização deste imposto foi acompanhada pela diminuição da sua expressão económica, representando, em 1984, apenas 3,4\% do total das receitas fiscais $-5,4 \%$ em 1978 (ibidem: 186).

De acordo com Carreira (1986), tal deveu-se aos elevados níveis de fraude e evasão fiscal dos contribuintes mais ricos e teve como consequência o agravamento da carga fiscal direta sobre os contribuintes da parte intermédia da distribuição. Segundo o autor, no início da década de 1980 os contribuintes mais penalizados com o aumento da carga fiscal direta sobre o rendimento foram os trabalhadores por conta de outrem: por um lado, as taxas do imposto profissional aumentaram bastante num período de duas décadas; por outro, ampliou-se também o peso deste tipo de rendimento para a formação da base do imposto complementar: 95\%, em 1984 (ibidem: 79). De facto, os salários eram o único tipo de rendimento que era tributado de forma progressiva quer ao nível da cédula, quer em sede de imposto complementar. A reforma introduzida no início da década de 1960, potencialmente vocacionada para uma maior personalização da tributação do rendimento, redundou no aumento da "preponderância dos elementos cedulares" e, do ponto de vista da coleta, na perda progressiva da relevância das receitas do imposto complementar (Decreto-Lei n. $\left.{ }^{\circ} 442-\mathrm{A} / 88\right) .{ }^{4}$

Criado como um tributo provisório, o imposto complementar permitiu uma relativa personalização e englobamento na tributação do rendimento. A sua aplicação foi, no entanto, bastante ineficaz e injusta. A matriz de tributação do rendimento em Portugal na segunda metade da década de 1980 caracterizava-se pelo seu anacronismo: o país era o único membro da OCDE

\footnotetext{
${ }^{4}$ Considerações constantes na introdução do DL 442-A/88, Diário da República n. ${ }^{\circ} 277 / 1988,1$. Suplemento, Série I de 1988-11-30. Lisboa: Ministério das Finanças.
} 
a tributar de forma essencialmente compartimentada o rendimento (Basto, 2009). Para corrigir estas questões e romper com a matriz cedular do sistema fiscal, urgia reformá-lo. Foi isso que se fez em 1988, com a aprovação do Código do Imposto sobre o Rendimento das Pessoas Singulares (CIRS).

\section{Capital e (semi)dualismo fiscal}

A reforma fiscal de 1988/1989 implicou uma alteração da "morfologia dos impostos" (Cunha, 1996). Autonomizou-se o âmbito legal de tributação das pessoas singulares e o das pessoas coletivas (empresas, sociedades comerciais, etc.) e, naquele caso, pretendeu-se superar uma das principais limitações do anterior sistema: a sua natureza eminentemente parcelar ou cedular. Para tal era necessário garantir a personalização do sistema fiscal, isto é, que a tributação do rendimento das pessoas singulares tivesse como referência a totalidade dos vários tipos de rendimentos auferidos num dado ano fiscal. O nível de tributação teria de ser determinado pelo volume monetário total do rendimento anual, tenha ele apenas uma fonte ou categoria, ou advenha de uma combinação de vários tipos de rendimentos. De acordo com Cunha (ibidem), presidente da Comissão da Reforma Fiscal de 1985-1988, o englobamento do rendimento foi um dos princípios axiais da proposta legislativa produzida por este órgão. As exceções a esta regra aplicavam-se, no articulado da referida proposta, apenas nos casos onde se verificasse "a impossibilidade de individualização de tais rendimentos para efeitos de englobamento, como acontecia com os juros dos depósitos bancários e os juros e dividendos de títulos ao portador não registados nem depositados" (ibidem: 66-67). Na prática, este tipo de exceções acabou por alargar-se e o princípio da unicidade da tributação do rendimento das pessoas singulares ficou enfraquecido desde a origem da reforma. ${ }^{5}$

A reforma de 1988/1989 procurou superar a matriz cedular do sistema fiscal português - no sentido da existência de "impostos diferenciados, regidos por diplomas legislativos diferentes, com declarações diferenciadas, etc.” (Basto, 2007: 25) -, mas a abundância de exceções ao princípio do englobamento do rendimento aí consagrado abriu, desde logo, o caminho

\footnotetext{
5 Paulo de Pitta e Cunha relata que, à última hora, o governo de Aníbal Cavaco Silva procurou alargar as exceções ao princípio do englobamento a todos os rendimentos da categoria $\mathrm{E}$ (rendimentos de capital) e $\mathrm{G}$ (incrementos patrimoniais). "Como é próprio das soluções de compromisso, cada lado averbou apenas meia vitória. Da exclusão integral das categorias E e G, como pretendia o Governo, passou-se à exclusão meramente parcial, como aceitara a Comissão. Mas o campo de aplicação das taxas liberatórias resultou muito mais amplo do que esta admitia, pois veio a abranger os rendimentos de quaisquer títulos, mesmo nominativos, e a assumir expressão permanente" (Cunha, 1996: 66-67).
} 
para o truncamento da unicidade fiscal do imposto sobre o rendimento das pessoas singulares (IRS). Esse condicionamento foi feito através da consagração legal de taxas liberatórias e especiais aplicáveis aos rendimentos de capital, passíveis de serem escolhidas pelos contribuintes como medidas de tributação autónoma em relação ao restante rendimento, nomeadamente aos rendimentos do trabalho e às pensões de reforma. ${ }^{6}$

$\mathrm{Na}$ primeira versão do CIRS eram estatuídas seis situações em que se aplicava o recurso a "taxas especiais liberatórias" (DL 442-A/88), quatro de forma obrigatória, duas de modo opcional. Em relação a estas últimas, e caso o contribuinte optasse por não englobar os rendimentos, o legislador previu que os rendimentos de capital (categoria E) provenientes de títulos ao portador e os lucros de depósitos bancários fossem retidos na fonte, com liberação da obrigação de imposto, à taxa de $25 \%$ e $20 \%$, respetivamente. Quanto aos rendimentos obrigatoriamente sujeitos a retenção na fonte e tributados liberatoriamente, a lei aplicou este regime aos rendimentos dos não residentes (com taxas variáveis, consoante o tipo de rendimento), aos rendimentos do jogo, lotarias e apostas mútuas, aos rendimentos provenientes de propriedade intelectual, usos de equipamentos que não constituam rendimentos prediais ou análogos, e "outros rendimentos de capitais, não mencionados nas alíneas anteriores, dos não residentes em Portugal" (ibidem). Previa-se também uma taxa especial de $10 \%$ aplicável às mais-valias realizadas com a venda de partes sociais e outros valores mobiliários - também neste caso o contribuinte podia optar pelo englobamento do rendimento. ${ }^{7}$

O CIRS foi tendo alterações sucessivas e aditamentos ao longo da década de 1990, que significaram um aumento do número de exceções ao princípio geral do englobamento dos rendimentos. Em meados da década de 1990, Cunha (1996: 76) avaliava deste modo a evolução da reforma do IRS:

Os factores de agravamento das entorses ao modelo de tributação global e progressiva tendem a intensificar-se, na medida em que não só não se procura sanar deficiências que vêm desde a primeira versão do Código, como se persiste em acentuar tais incorreções: extensão do recurso a taxas liberatórias; generalização da incomunicabilidade das perdas. Dividido em cédulas entre si cada vez mais incomunicáveis, com uma larguíssima zona de rendimentos de capitais, em sentido amplo, subtraída

\footnotetext{
6 "Tais taxas dizem-se liberatórias porquanto liberam (libertam) das obrigações de declaração, de englobamento e pagamento pelo contribuinte (a obrigação de imposto considera-se cumprida com a retenção na fonte efetuada pela entidade pagadora). Acontece, pois, uma substituição fiscal" (Morais, 2016: 166).

${ }^{7}$ Ao contrário das taxas liberatórias, as taxas especiais aplicam-se tipicamente a rendimentos que não são retidos na fonte.
} 
ao regime geral da globalização de rendimentos, e passível de taxas liberatórias que se configuram como impostos reais separados, o imposto sobre o rendimento das pessoas singulares, não obstante a sua aparente e formal 'unicidade', transmite-nos a desconfortável impressão de parentesco próximo com as figuras fiscais anacrónicas que com ele se pretenderam suplantar, assumindo, afinal, traços de inquietante continuidade com o anterior modelo de imposto profissional - imposto complementar, sobre o qual já pesavam as acusações, agora renovadas, de penalização, em tributação progressiva, dos rendimentos do trabalho, com perverso desagravamento dos de outras categorias, em atentado indiscutível aos princípios da equidade horizontal.

A tendência de dualização do sistema foi atenuada no início do milénio, em particular com a publicação da Lei n. ${ }^{\circ} 30-\mathrm{G} / 2000 .{ }^{8}$ Cunha (2008) considerou que esse diploma possibilitou uma "ligeira redução do recurso a taxas liberatórias”. Nabais (2004: 460) densificou esta ideia:

Sujeitaram-se os rendimentos das ações nominativas ou ao portador ao seu englobamento para efeitos de determinação da taxa aplicável, relativamente aos rendimentos do ano de 2001 e ao seu englobamento para efeitos da sua tributação a partir de 1 de Janeiro de 2002 [...]. Foi profundamente modificado o regime de tributação das mais-valias apuradas no âmbito de atividades empresariais e profissionais, das mais-valias financeiras e, bem assim, das mais-valias realizadas com a transmissão de ativos do imobilizado corpóreo quando objeto de reinvestimento.

Contudo, algumas destas disposições foram anuladas ou não chegaram a entrar em vigor e, em geral, as lógicas de dualização do IRS tenderam a aprofundar-se até à atualidade - com especial destaque para a tributação a uma taxa proporcional de $28 \%$ dos rendimentos prediais, a partir de 2013.

A tributação direta do rendimento pessoal em Portugal nas últimas décadas tem-se caracterizado, portanto, por um hibridismo que tende a autonomizar e a beneficiar os rendimentos de capital e similares em relação aos rendimentos do trabalho e pensões. Um dos principais objetivos da reforma de 1988/1989 prendia-se com a personalização do sistema tributário português, nunca alcançado pelo imposto complementar, a qual implicava uma lógica de englobamento dos rendimentos. O espartilhamento das regras aplicáveis a vários tipos de rendimentos, nomeadamente a possibilidade de retenção na fonte a título liberatório de certos rendimentos de capital e mais-valias mobiliárias, mas também, a partir de 2013, a tributação proporcional dos rendimentos

${ }_{8}^{8}$ Lei n. $^{\circ}$ 30-G/2000, Diário da República n. ${ }^{\circ}$ 299/2000, 3. . Suplemento, Série I-A de 2000-12-29. Lisboa: Assembleia da República. 
prediais, condicionou fortemente a concretização desse objetivo. A situação atual espelha isso mesmo. Se o projeto inicial da reforma de 1988 era o de aplicar este tipo de regime apenas a título excecional, tal não se verificou na letra da lei que entrou em vigor no ano seguinte, tendo essa realidade conhecido, nas suas várias manifestações, um aprofundamento ao longo das últimas décadas. O cariz parcelar da tributação que se queria ultrapassar com a reforma de 1988/1989 manteve, pelo menos em parte, a sua presença no desenho do novo sistema tributário e é, na atualidade, um dos traços estruturais do IRS português (Pereira, 2019; Faustino, 2014; Basto, 2009, 2007).

De facto, a maior parte dos rendimentos que têm a sua origem no património mobiliário e imobiliário é tributada a uma taxa proporcional, autónoma em relação à totalidade dos rendimentos $\mathrm{e}$, por isso, independente da real capacidade contributiva de cada um. A autonomização tributária dos rendimentos patrimoniais - em particular os rendimentos de capital, prediais e mais valias-mobiliárias - passou a ser a regra e não a exceção do sistema fiscal português (Pereira, 2019). A tributação do rendimento em Portugal coloca o país na família dos sistemas fiscais do tipo "semi-dual", definida pela OCDE da seguinte forma: "aplica diferentes taxas nominais a tipos de rendimentos diferenciados, taxando tipicamente algumas formas de capital (singular ou coletivo) a níveis baixos ou proporcionais e as restantes formas de rendimento a taxas mais altas e progressivas" (OECD, 2006; tradução do autor). ${ }^{9}$

Não é fácil medir estatisticamente as iniquidades fiscais associadas a esta lógica semi-dual. As estatísticas disponibilizadas pela Autoridade Tributária não apresentam a distribuição do rendimento, por categoria de rendimento e quantil. Além disso, em particular para os rendimentos de capital em sentido estrito (categoria E), a informação apresentada não dá conta do valor total desse tipo de rendimento e do imposto liquidado em relação a essa categoria (precisamente pelo facto de esses rendimentos serem retidos na fonte à taxa liberatória e não serem de englobamento obrigatório).

A informação disponível evidencia a existência de uma concentração expressiva do património e do rendimento gerado a partir daí nos grupos mais favorecidos. Em relação ao stock, veja-se, a título ilustrativo, que o valor médio

\footnotetext{
${ }^{9}$ Os outros tipos de sistemas tributários traçados pela OCDE, uns de natureza mais teórica e abstrata, outros operacionalizados pelos sistemas fiscais dos países, são: o sistema abrangente ou de imposto único (comprehensive income tax, que corresponde ao perfil de imposto único, sintético previsto na Constituição portuguesa); o sistema dual (todos os rendimentos são taxados a um mesmo nível e, sobre os que excedem um determinado nível, nomeadamente os rendimentos do trabalho e pensões, incidem taxas progressivas); o sistema proporcional, no qual se aplica uma mesma taxa a todos os rendimentos, independentemente do seu montante (solução adotada em vários países do leste europeu e do báltico); e, por último, o sistema de tributação da despesa (expenditure tax), o qual consiste na tributação apenas do rendimento despendido em consumo.
} 
dos ativos financeiros dos 10\% do topo da distribuição da riqueza e do rendimento é cerca de oito e seis vezes superior, respetivamente, em relação ao valor médio apurado para o total da população que é titular daquele tipo de recursos (Costa, 2016) - uma parte dos agregados domésticos não é detentora deste tipo de recursos, pelo que o nível de desigualdade para o total da população será ainda maior. Estes dados nada dizem, no entanto, acerca do fluxo, isto é, do rendimento gerado pela titularidade de ativos mobiliários e imobiliários.

Os dados do European Union Statistics on Income and Living Conditions (EU-SILC) são limitados no que à análise da distribuição dos rendimentos de capital/propriedade diz respeito, já que a sua natureza amostral não permite analisar com precisão os grupos restritos do topo $(1 \%, 0,1 \%$ ou $0,01 \%$ com rendimentos mais elevados), nos quais, como se referiu atrás, os rendimentos de capital tendem a ter um peso relativo e uma magnitude económica maiores. Apesar destes condicionalismos, esta fonte fornece alguns indícios em relação à distribuição deste tipo de rendimentos, em particular a sua forte concentração na parte superior da distribuição. ${ }^{10} \mathrm{O}$ Gráfico 1 demonstra que em Portugal, no ano de 2014, cerca de $51 \%$ e $37 \%$ dos rendimentos de capital/ /propriedade eram auferidos pelo decil e vintil do topo da distribuição do rendimento bruto equivalente, respetivamente. Acima, portanto, do apurado para as remunerações do trabalho e pensões de velhice.

\section{GRÁFICO 1 - Proporção do rendimento bruto equivalente auferido pelos $10 \%$ e $5 \%$ da parte superior da distribuição, Portugal (2014) (\%)}

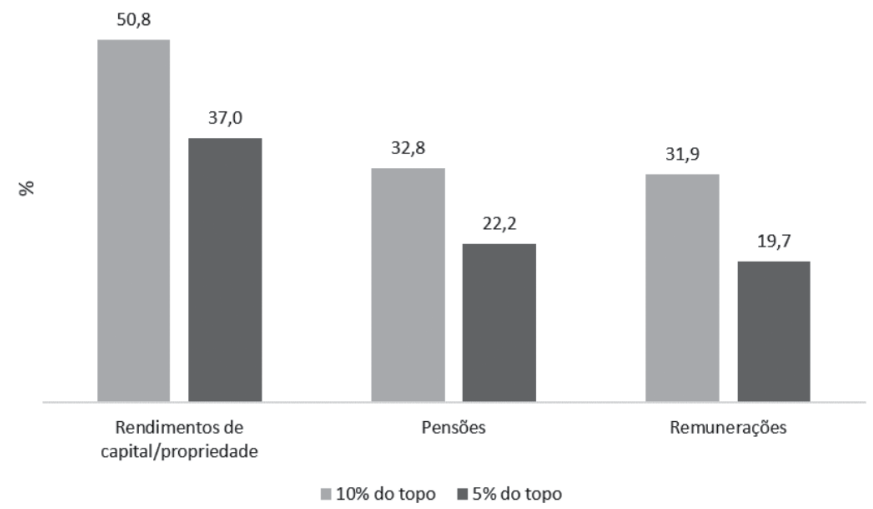

Fonte: cálculos do autor a partir dos microdados do EU-SILC 2015.

${ }_{10} \mathrm{Na}$ computação dos rendimentos de capital/propriedade teve-se em consideração os juros, dividendos e lucros de aplicações financeiras, as rendas de propriedade imobiliária e as pensões privadas. 
Vários estudos demonstram que a fiscalidade direta em Portugal tem um efeito redistributivo comparativamente elevado (Cantante, 2019; Alves, 2012; Joumard et al., 2012; Rodrigues et al., 2012). Tal deve-se, na verdade, ao enquadramento fiscal dos rendimentos do trabalho e das pensões - as categorias de rendimento sobre as quais a progressividade fiscal incide. A tributação proporcional de certos rendimentos tende a ter um efeito contrário. Tal como é enunciado por Pereira (2019: 51),

O facto de os rendimentos de capitais e as mais-valias mobiliárias assumirem, em princípio, maior relevo nos rendimentos dos contribuintes com uma capacidade económica mais elevada (e que, portanto, se situariam nos escalões mais elevados de tributação), permite admitir que as taxas liberatórias e especiais que tributam estes tipos de rendimentos tenham, com frequência, um efeito regressivo.

\section{A tributação progressiva dos rendimentos de capital}

A criação, no final da década de 1980, de um imposto único para as pessoas singulares em Portugal ocorreu num contexto internacional em que se começava já a abandonar esse tipo de modelo (Morais, 2016; Basto, 2009). Se, em 1974, Portugal "seria talvez o único país a não praticar a tributação sintética do rendimento” (Basto, 2009: 275), quando o CIRS entrou em vigor o hibridismo tributário, nas suas várias formulações, começava a impor-se a nível internacional - nos Estados Unidos de Ronald Reagan ou nos países do norte da Europa no início da década de 1990. Nos dias de hoje, este tipo de regimes mistos está generalizado no universo de países da União Europeia e da OCDE (Ernst and Young, 2016; Schellekens, 2015; Basto, 2007; OECD, 2006).

No contexto português, a tributação proporcional de certo tipo de rendimentos levanta questões de natureza jurídica, no sentido em que, para alguns, configura uma clara violação do artigo 104/1 da Constituição da República Portuguesa (Canotilho e Moreira, 2007; Sanches, 1998). ${ }^{11}$ Quer a unicidade (que implica que todos os tipos de rendimentos sejam englobados), quer a progressividade (que determina a gradação do imposto devido de acordo com o volume do rendimento) da tributação do rendimento pessoal estatuídas na fonte de direito primordial do sistema jurídico português são princípios dificilmente compagináveis com o regime tributário aplicável a certos rendimentos. Canotilho e Moreira (2007: 1099-1100) sintetizam esta questão:

11 "Art. $104^{\circ}-1$. O imposto sobre o rendimento pessoal visa a diminuição das desigualdades e será único e progressivo, tendo em conta as necessidades e os rendimentos do agregado familiar”. 
Os requisitos de unicidade e progressividade do imposto, sem exceções, retiram base constitucional às chamadas taxas liberatórias em relação a determinados rendimentos (por exemplo, rendimentos de capital), para o efeito tributados separadamente, pois que no caso de o contribuinte só ser titular de tais rendimentos o imposto deixa de ser único e torna-se comparativamente menos progressivo. Por sua vez, o requisito da progressividade afasta decididamente as soluções de "flat rate" (taxa uniforme), que têm sido adotadas ultimamente em alguns países, em homenagem a uma alegada "simplificação fiscal".

Este tipo de taxas coloca, de facto, problemas sérios de igualdade tributária horizontal, já que o esforço fiscal exigido a indivíduos com uma capacidade contributiva idêntica pode ser bastante diferenciado, tendo em conta a composição do rendimento de cada um. Tal como é referido por Pereira,

uma capacidade contributiva revelada através de rendimentos de capitais ou de mais-valias mobiliárias é beneficiada com uma tributação efetiva potencialmente bastante inferior àquela que onera igual capacidade contributiva revelada através de rendimentos do trabalho ou de pensões. (2019: 52)

Os imperativos de simplificação tributária e administrativa, a estimulação da poupança e do investimento e, principalmente, o risco da fuga de capitais são os argumentos tipicamente convocados, na doutrina jurídica e não só, para justificar o regime das taxas liberatórias. Em relação a este último, refere-se que no contexto de um mundo globalizado, no qual os capitais circulam livremente e os Estados concorrem entre si para atrair investimentos, instituir regimes fiscais que enquadrem do mesmo modo os rendimentos gerados pelos fatores de produção móveis (o capital) e os que têm uma natureza essencialmente imóvel (o trabalho) é impraticável. Embora admitam que a tributação proporcional do capital levanta sérios problemas de constitucionalidade, Miranda e Medeiros (2006: 226) entendem que a existência desse tipo de regimes é inevitável. Nabais (2016: 163), por seu turno, defende que essa inevitabilidade, gerada pela

internacionalização e globalização dos mercados [...], reclama uma harmonização adequada daqueles requisitos constitucionais do imposto sobre o rendimento pessoal com o mencionado princípio da praticabilidade, harmonização que passa pela ponderação dos referidos bens jurídicos constitucionais.

Basto (2009: 277) concorda com essa afirmação, concluindo que "muito dificilmente se conseguiria hoje uma aproximação mínima ao modelo puro da tributação sintética que parece constituir a opção da Constituição”. 
Esta questão tem sido pouco debatida no campo político e apenas por uma vez, em 1995, o Tribunal Constitucional (TC) foi chamado a pronunciar-se sobre a conformidade constitucional destes regimes. ${ }^{12} \mathrm{Tem}$, neste sentido, existido como que um assentimento tácito acerca da existência de taxas proporcionais aplicáveis aos rendimentos de capital, mesmo que as mesmas sejam, no mínimo, bastante discutíveis do ponto de vista constitucional. Para utilizar a linguagem luhmanniana, o sistema jurídico tem sido muito pouco "irritado" pelo sistema político e pelo debate público em geral (Luhmann, 2004). Apesar de o risco da fuga de capitais ser uma espada que pende sobre as políticas fiscais dos países - e de um pequeno país como Portugal em particular - importa encontrar soluções equilibradas que permitam conciliar imperativos de ordem económica e financeira, com preocupações de natureza valorativa.

Independentemente das razões jurídicas que se apõem na discussão da conformidade constitucional das taxas liberatórias e regimes análogos, não parece ser politicamente viável optar pela sua simples abolição e pela obrigatoriedade do englobamento da totalidade do rendimento - o regime de pendor mais redistributivo e conforme à letra e espírito da Constituição da República Portuguesa. A existência destes regimes implica necessariamente que o princípio da unicidade tributária não seja respeitado, mas as iniquidades daqui resultantes poderiam ser mitigadas por via da tributação progressiva dos rendimentos de capital (em sentido lato). Numa solução deste tipo assume-se, de forma mais ou menos pronunciada, o sacrifício do princípio da unicidade fiscal, mas aplica-se aos rendimentos de capital um princípio de progressividade tipicamente usado, nos dias de hoje, na tributação dos rendimentos do trabalho e das pensões (Brys et al., 2016). Não existem muitos casos na atualidade em que este tipo de regime fiscal seja implementado. Mas existem alguns: a Dinamarca e o Reino Unido apresentam soluções que vão neste sentido, embora difiram em alguns aspetos.

$\mathrm{Na}$ Dinamarca, os dividendos são retidos na fonte a uma taxa de $27 \%$, mas quando o valor desse rendimento excede as 49900 coroas dinamarquesas aplica-se uma taxa suplementar de $15 \%$ ao remanescente. Acima deste limiar, os dividendos são, portanto, taxados a $42 \%$. O Reino Unido oferece também um exemplo interessante: no ano de 2015, aplicavam-se nesse país taxas progressivas a certos rendimentos de capital. Os juros eram taxados de

\footnotetext{
${ }^{12}$ O TC não se pronunciou sobre a desconformidade constitucional das taxas liberatórias defendida pela bancada parlamentar do Partido Comunista no seu pedido de fiscalização, argumentando que as normas em causa tinham conhecido mudanças significativas desde a sua versão originária de 1989 - facto que, segundo o TC, o impedia de se pronunciar substantivamente sobre a inconstitucionalidade do regime liberatório no momento do pedido.
} 
acordo com os escalões e as taxas gerais em vigor, enquanto os dividendos, embora tendo os mesmos escalões como referência, eram taxados a níveis inferiores aos rendimentos do trabalho, pensões e juros. No último escalão (rendimentos acima de 150 mil libras esterlinas), os dividendos eram taxados a $37,5 \%$ (embora este valor fosse diminuído por um crédito fiscal), enquanto os demais rendimentos eram-no a $45 \%$. Quer no caso dos dividendos, quer no caso dos juros, as taxas que se lhes aplicam dependem do nível agregado de rendimento do contribuinte (Ernst and Young, 2016; Schellekens, 2015). Embora possibilite que os dividendos sejam taxados a um nível inferior em relação a outros rendimentos, este regime estatui, portanto, que a definição da taxa a pagar obedece a critérios de unicidade fiscal.

A tributação progressiva dos rendimentos de capital não resolve todas as injustiças e disfuncionalidades dos sistemas fiscais. De facto, essa injustiça não é anulada se o nível de tributação for mais baixo do que o aplicado aos rendimentos do trabalho e pensões e se houver uma autonomização de determinado rendimento face ao rendimento global - como acontece na Dinamarca em relação aos dividendos.

Em Portugal, em 2019, a taxa de 28\% aplicável a mais-valias mobiliárias, rendimentos prediais, ${ }^{13}$ juros e dividendos corresponde aproximadamente à taxa normal do terceiro escalão (10 700 euros a 20261 euros) e à taxa média do quinto escalão (25000 euros a 36856 euros). Neste ano, a taxa normal do último escalão era de $48 \%$ e de $53 \%$ para rendimentos acima dos 250 mil euros. A tributação dos rendimentos de capital mais elevados (no seu sentido lato, incluindo rendimentos de propriedade imobiliária e mais-valias mobiliárias) é feita, portanto, num patamar bastante inferior quando comparada com o que se verifica em relação aos rendimentos do trabalho e pensões. A densificação do princípio da progressividade inscrito num regime como o que aqui se está a esboçar passaria, então, pela definição de dois ou mais escalões que enquadrassem o nível de tributação dos rendimentos de capital. Num patamar mais baixo do que as taxas vigentes no regime normal, mas, pelo menos em relação ao escalão mais elevado, acima do nível atual de tributação dos rendimentos de capital.

A criação de um modelo de tributação progressiva dos rendimentos de capital em Portugal poderia, portanto, concretizar-se de formas diferenciadas. Desde logo, no que diz respeito aos tipos de rendimentos de capital nele incluídos. Numa abordagem mais conservadora eleger-se-iam apenas os dividendos, os juros ou as mais-valias mobiliárias como estando sujeitos

${ }_{13}$ A Lei n. ${ }^{\circ}$ 3/2019 (Diário da República n. ${ }^{\circ}$ 6/2019, Série I de 2019-01-09) introduziu reduções na taxa aplicável aos rendimentos prediais consoante a duração do contrato de arrendamento. 
a uma tributação progressiva. No caso de uma solução mais progressista optar-se-ia por incluir outros rendimentos que decorrem da titularidade de património, nomeadamente os rendimentos prediais. A calibragem de um modelo de tributação progressiva dos rendimentos de capital poderia também obedecer a graus diferenciados de autonomização tributária. Numa versão mais dualista, não existiria qualquer comunicabilidade nem entre os rendimentos de capital e os demais rendimentos, nem entre os vários tipos de rendimentos de capital. A definição da taxa a pagar por cada tipo de rendimento de capital basear-se-ia apenas no seu montante, independentemente da existência de mais proventos. Se o modelo for, pelo menos parcialmente, informado pelo princípio da unicidade, poder-se-ia optar por uma solução próxima da existente no Reino Unido, onde os dividendos são taxados a um nível mais baixo do que os demais rendimentos, mas estes são tidos em linha de conta para o cálculo do escalão de rendimento que serve de referência para a aplicação do imposto devido. Ou seja, um regime de tributação dos rendimentos de capital baseado num englobamento parcial ou imperfeito.

A adoção de um modelo com o perfil traçado nos parágrafos anteriores não resolveria todos os problemas de conformidade constitucional do atual regime semi-dual, mas certamente mitigaria os problemas relacionados com o princípio da progressividade e também, no caso de uma solução guiada por regras de englobamento parcial dos rendimentos, os atinentes ao princípio da unicidade.

Do ponto de vista do seu alcance, uma reforma com estas características ficaria certamente bastante aquém da preconizada por Piketty (2013) em relação à tributação progressiva do capital. Desde logo porque o objeto das medidas aqui propostas é o rendimento, o fluxo monetário produzido pelo capital, e não o acervo ou stock patrimonial, mas também devido ao facto de as mesmas admitirem formas de transigência mais ou menos significativas em relação ao princípio do englobamento do rendimento. Num momento em que as inevitabilidades são frequentemente usadas como um argumento para nada fazer em relação a injustiças várias, é necessário encontrar e propor soluções viáveis, equilibradas, compromissórias, que permitam mitigar problemas e propiciar mais igualdade. Soluções que admitam que o modelo puro de tributação sintética que emerge da Constituição portuguesa é de difícil operacionalização nos dias de hoje, mas que entendam ser possível, apesar das limitações decorrentes da globalização financeira, modelar o sistema de tributação do rendimento das pessoas singulares no sentido de uma maior igualdade e justiça redistributiva. São esses os objetivos que norteiam os pilares normativos da proposta aqui apresentada. 


\section{Conclusão}

Embora seja um sistema progressivo, a fiscalidade sobre o rendimento das pessoas singulares em Portugal caracteriza-se pelo seu cariz semi-dual, um molde institucional que implica que os rendimentos de capital tenham um enquadramento fiscal mais favorável do que os rendimentos do trabalho e pensões. Esta injustiça é transversal a grande parte dos países e decorre de imperativos de atração de investimento e poupança, mas também do receio dos Estados de uma possível fuga de capitais. O favorecimento fiscal dos rendimentos de capital surge, neste sentido, como uma inevitabilidade, uma decisão pragmática, mesmo que muito possivelmente inconstitucional. Uma imposição do mercado ao poder regulatório e redistributivo dos Estados.

A tributação progressiva dos rendimentos de capital, tal como aqui foi equacionada, é uma proposta de alcance limitado, embora permita introduzir mais justiça nos processos de redistribuição fiscal do rendimento. A prossecução de objetivos mais ambiciosos na tributação do rendimento, e também da riqueza, depende da sua operacionalização a uma escala internacional, pela qual se pudessem evitar, ou pelo menos mitigar, fenómenos de competição fiscal e de ocultação de património, não só ao nível dos rendimentos pessoais, mas também no que diz respeito aos lucros das empresas. Veja-se que, nos EUA, 111 das 288 empresas da Fortune 500 que deram lucro entre 2008 e 2012 pagaram $0 \%$ de impostos ou foram até reembolsadas (Dietsch, 2015: 5). Dificilmente se pode justificar que as grandes multinacionais não paguem impostos ou paguem impostos baixíssimos sobre os seus lucros, usando estratégias de planeamento fiscal e tendo como abrigo Estados que praticam políticas fiscais desleais e/ou, em certos casos, muito pouco transparentes. Mais difícil ainda é a defesa dos países que oferecem segredo fiscal - os chamados paraísos fiscais. É através deles que os mais ricos ocultam património e rendimento, iludindo as autoridades nacionais acerca da sua real capacidade contributiva. Atualmente, mais de $10 \%$ do PIB global está ocultado em paraísos fiscais (Alvaredo et al., 2017: 20).

No caso português, têm sido noticiados vários casos de ocultação de património em paraísos fiscais. ${ }^{14} \mathrm{O}$ Regime Excepcional de Regularização Tributária, por seu lado, que funcionou em boa medida com uma forma de perdão fiscal aos contribuintes mais ricos, permitiu desocultar ao longo da última década vários milhares de milhões de euros e é indício relevante acerca da grandeza do fenómeno da evasão fiscal ao nível do topo.

$\overline{14}$ Ver, por exemplo, https://expresso.pt/revista-de-imprensa/2018-11-09-Offshores.-Fisco-investiga-256-portugueses-suspeitos-de-ocultacao-de-fundos. 
As alterações que se verificaram nas últimas décadas no direito fiscal, nomeadamente nas normas e princípios que enquadram a tributação do rendimento pessoal, são uma das faces mais ilustrativas da rarefação da capacidade regulatória dos Estados em relação ao avanço das lógicas e demandas do mercado, conducentes ao aprofundamento das desigualdades económicas e das injustiças. Importa por isso contrariar este tipo de tendência, nos planos nacional e internacional, de forma mais ou menos ambiciosa, reforçando a capacidade redistributiva do Estado e o seu papel na mitigação das assimetrias económicas e sociais.

Revisto por Ana Sofia Veloso

\section{Referências bibliográficas}

Aaberge, Rolf; Atkinson, Anthony B.; Königs, Sebastian (2018), "From Classes to Copulas: Wages, Capital, and Top Incomes", The Journal of Economic Inequality, 16(2), 295-320. Consultado a 01.09.2018, em https://link.springer.com/article/10.1007/s10888018-9386-x.

Alvaredo, Facundo (2010), "Top Incomes and Earnings in Portugal 1936-2005”, in Anthony B. Atkinson; Thomas Piketty (orgs.), Top Incomes: A Global Perspective. Oxford: Oxford University Press, 560-624.

Alvaredo, Facundo; Atkinson, Anthony B.; Piketty, Thomas; Saez, Emmanuel (2013), "The Top 1 Percent in International and Historical Perspective", Journal of Economic Perspectives, 27(3), 3-20. Consultado a 16.12.2013, em https://www.aeaweb.org/ articles?id=10.1257/jep.27.3.3. DOI: $10.1257 /$ jep.27.3.3

Alvaredo, Facundo; Chancel, Lucas; Piketty, Thomas; Saez, Emmanuel; Zucman, Gabriel (coords.) (2017), World Inequality Report 2018. Paris: World Inequality Lab. Consultado a 16.01.2018, em http://wir2018.wid.world/files/download/wir2018full-report-english.pdf.

Alves, Nuno (2012), "Uma perspetiva sobre a redistribuição do rendimento em Portugal e na União Europeia”, Boletim Económico, 18(4), 41-58. Consultado a 18.09.2014, em https://www.bportugal.pt/sites/default/files/anexos/papers/ab201214_p.pdf.

Atkinson, Anthony B. (2015), Inequality. What Can Be Done? London: Harvard University Press.

Basto, José Guilherme Xavier de (2007), IRS: incidencia real e determinação dos impostos líquidos. Coimbra: Coimbra Editora.

Basto, José Guilherme Xavier de (2009), "A Constituição e o sistema fiscal", Revista de Legislação e de Jurisprudência, 138(3956), 271-284.

Brys, Bert; Matthews, Stephen; Owens, Jeffrey (2011), "Tax Reform Trends in OECD Countries", OECD Taxation Working Papers, 1. Consultado a 10.01.2017, 
em https://www.oecd-ilibrary.org/docserver/5kg3h0xxmz8t-en.pdf?expires $=158$ 0145054\&id $=\mathrm{id} \&$ accname $=$ guest $\&$ checksum $=8715979$ A6C0C721B409FC414C AEA5969. DOI: $10.1787 / 5 \mathrm{~kg} 3 \mathrm{~h} 0 x x m z 8 t-e n$

Brys, Bert; Perret, Sarah; Thomas, Alastair; O’Reilly, Pierce (2016), "Tax Design for Inclusive Economic Growth", OECD Taxation Working Papers, 26. Consultado a 10.01.2017, em https://www.oecd-ilibrary.org/docserver/5jlv74ggk0g7-en.pdf?exp ires $=1580145580 \& \mathrm{id}=\mathrm{id} \&$ accname $=$ oid $037823 \&$ checksum $=4$ A29781F9015E40EE 3FCE333141DD026. DOI: 10.1787/5jlv74ggk0g7-en

Canotilho, José Joaquim Gomes; Moreira, Vital (2007), Constituição da República Portuguesa anotada - Vol. I. Coimbra: Coimbra Editora.

Cantante, Frederico (2019), O risco da desigualdade. Coimbra: Edições Almedina.

Cantante, Frederico; Carmo, Renato Miguel do; Alves, Nuno de Almeida; Costa, António Firmino da (2016), "Trends in Income Inequality: Comparing the United States and Portugal", Portuguese Journal of Social Science, 15(3), 367-386. DOI: 10.1386/ pjss.15.3.367_1

Carreira, Henrique Medina (1986), "Alguns aspectos sociais, económicos e financeiros da fiscalidade portuguesa”, Análise Social, XXII(90), 59-91. Consultado a 23.10.2015, em http://analisesocial.ics.ul.pt/documentos/1223483043S1mOT0jq6Aw77LP8.pdf.

Costa, Sónia (2016), "Situação financeira das famílias em Portugal: uma análise com base nos dados do ISFF 2013”, Revista de Estudos Económicos, II(4), 15-59.

Cunha, Paulo de Pitta e (1996), A fiscalidade nos anos 90 (estudos e pareceres). Coimbra: Edições Almedina.

Cunha, Paulo de Pitta e (2008), "A pseudo-reforma fiscal do final do século XX e o regime simplificado do IRS”, Revista de Finanças Públicas, 1, 15-34.

Dietsch, Peter (2015), Catching Capital. The Ethics of Tax Competition. Oxford: Oxford University Press.

Ernst and Young (2015), "Worldwide Personal Tax Guide: Income Tax, Social Security and Immigration 2015-16". London: Ernst and Young.

Faustino, Manuel (2014), "O IRS 25 anos depois", Revista de Finanças Públicas, VII(2), 67-111.

Förster, Michael; Llena-Nozal, Ana; Nafilyan, Vahé (2014), "Trends in Top Incomes and Their Taxation in OECD Countries", OECD Social, Employment and Migration Working Papers, 159. Consultado a 06.05.2015, em https://www.oecd-ilibrary.org/docserver/5jz43jhlz87f-en.pdf?expires=1580146339\&id=id\&accna me $=$ oid037823 \&checksum=9FCEA5DB96DEC521F89F4DFEBDC5F558. DOI: 10.1787/5jz43jhlz87f-en

Guilera, Jordi (2010), "The Evolution of Top Income and Wealth Shares in Portugal since 1936", Revista de Historia Económica, 28(1), 139-171. Consultado a 20.03.2014, em https://e-archivo.uc3m.es/bitstream/handle/10016/20213/RHE-2010-XXVIIIGuilera.pdf?sequence=1. DOI: 10.1017/S0212610909990073 
Joumard, Isabelle; Pisu, Mauro; Bloch, Debra (2012), "Less Income Inequality and more Growth - Are They Compatible? Part 3. Income Redistribution Via Taxes and Transfers across OECD Countries”, OECD Economics Department Working Papers, 926. Consultado a 15.09.2013, em https://www.oecd-ilibrary. org/docserver/5k9h296b1zjf-en.pdf?expires=1580147437\&id=id\&accname= oid037823 \&checksum=FED493430C0ABADBDD5E019AB449C2E6. DOI: $10.1787 / 5 \mathrm{k} 9 \mathrm{~h} 296 \mathrm{~b} 1 \mathrm{zjf}-\mathrm{en}$

Landais, Camille ; Piketty, Thomas; Saez, Emmanuel (2011), Pour une révolution fiscale. Paris: Éditions du Seuil.

Luhmann, Niklas (2004), Law as a Social System. Oxford: Oxford University Press.

Milanović, Branko (2011), The Haves and the Have-Nots. A Brief and Idiosyncratic History of Global Inequality. New York: Basic Books.

Milanović, Branko (2016), Global Inequality. A New Approach for the Age of Globalization. Cambridge: Harvard University Press.

Miranda, Jorge; Medeiros, Rui (2006), Constituição portuguesa anotada - Tomo II. Coimbra: Coimbra Editora.

Morais, Rui Duarte (2016), Sobre o IRS. Coimbra: Edições Almedina.

Nabais, José Casalta (2004), Direito fiscal. Coimbra: Edições Almedina.

Nabais, José Casalta (2016), Direito fiscal. Coimbra: Edições Almedina.

OECD (2006), Fundamental Reform of Personal Income Tax. Paris: OECD Publications.

OECD (2008), Growing Unequal. Paris: OECD Publications.

OECD (2014), "Focus on Top Incomes and Taxation in OECD Countries: Was the Crisis a Game Changer?”. Consultado a 08.05.2015, em http://www.oecd.org/social/ OECD2014-FocusOnTopIncomes.pdf.

Pereira, Paula Rosado (2019), Manual de IRS. Coimbra: Edições Almedina.

Piketty, Thomas (2013), Le capital au XxI siècle. Paris: Éditions du Seuil.

Rodrigues, Carlos Farinha (coord.); Figueiras, Rita; Junqueira, Vítor (2012), Desigualdade económica em Portugal. Lisboa: FFMS.

Sanches, José Luís Saldanha (1984), "O imposto complementar como imposto de rendimento”, Revista Jurídica, 4, 185-221.

Sanches, José Luís Saldanha (1998), Manual de direito fiscal. Lisboa: Lex.

Schellekens, Marnix (org.) (2015), European Tax Handbook 2015. Amsterdam: IBFD Publications. 
Artigo recebido a 26.01.2018

Aprovado para publicação a 09.09.2019

\section{Frederico Cantante}

CoLABOR, Laboratório colaborativo para o Trabalho, Emprego e Proteção Social

Rua das Taipas, 1, 1250-264 Lisboa

Contacto: frederico.cantante@colabor.pt

ORCID: https://orcid.org/0000-0001-5287-7769

\section{Progressive Taxation of Capital Income}

This paper focuses on personal income taxation in Portugal. Firstly, the analysis focuses on the evolution of income tax prior do the IRS Code of 1989. Afterwards, we shed light on the continuities of the IRS reform with the previous tax system, namely its semi-dualist profile, which challenges the principles of unicity and progressivity of the Portuguese Constitution. Finally, we propose some policy orientations that could promote greater fairness in capital income taxation.

Keywords: income redistribution; income taxation; Portugal; tax law; taxes.

\section{La taxation progressive sur les revenus du capital}

Cet article se concentre sur l'impôt sur les revenus des personnes physiques au Portugal. Dans un premier temps, nous analyserons l'évolution de l'impôt sur le revenu (IR) dans les décennies précédant l'entrée en vigueur du Code de l'IR en 1989. Par la suite, nous examinerons les continuités de cette législation face à un passé à dépasser, en particulier la nature semi-duale du système d'impôt sur le revenu, qui remet en question les principes de l'unicité et de la progressivité fiscale inscrites dans la Constitution de la République portugaise. Finalement, nous discuterons certaines solutions qui pourraient introduire une plus grande justice dans la taxation des revenus du capital. Mots-clés: droit fiscal; Portugal; redistribution des revenus; taxation du revenu; taxes. 
